\title{
LAS INSTITUCIONES EUROPEAS ANTE LA CRISIS DEL ESTADO DE DERECHO EN HUNGRÍA Y POLONIA
}

\section{The European Institutions in the face of the Rule of law crisis in Hungary and Poland}

\author{
BELÉN BECERRIL ATIENZA \\ Universidad CEU San Pablo \\ becati@ceu.es
}

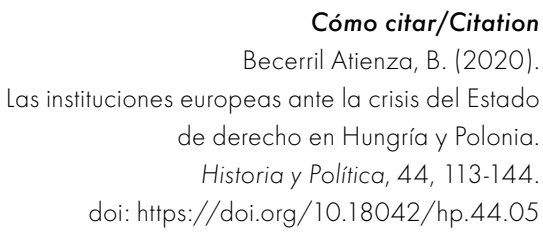

(Recepción: 06/11/2019; evaluación: 20/05/2020; aceptación: 15/06/2020; publicación: 27/11/2020)

\section{Resumen}

Este artículo aborda la crisis del Estado de derecho en Hungría y Polonia, situándola en el marco de la historia de la integración europea. Desde mediados de los años noventa, la Unión se fue dotando progresivamente de procedimientos específicos con el fin de que sus instituciones pudiesen responder a una eventual vulneración de sus valores por parte de un Estado miembro. Este proceso respondía particularmente a la inminencia de una quinta ampliación cuya dimensión no tenía precedentes y que habría de incorporar a Estados de corta trayectoria democrática. Ańos después, en un contexto marcado por el auge de los populismos, la deriva iliberal de los Gobiernos húngaro y polaco ha provocado el primer uso de los nuevos procedimientos, poniendo de manifiesto su insuficiencia ante una crisis de esta naturaleza y mostrando los límites de la capacidad de influencia de la Unión Europea después de la adhesión. 


\title{
Palabras clave
}

Integración europea; Estado de derecho; quinta ampliación; Polonia; Hungría.

\begin{abstract}
This article addresses the crisis of the rule of law in Hungary and Poland, in the context of the history of European integration. Since the mid-1990s, the Union has been gradually equipping itself with specific procedures so that its institutions can respond to a possible violation of its values by a Member State. This process responded particularly to the imminence of a fifth enlargement of an unprecedented dimension, which would incorporate States with a short democratic background. Years later, in a context marked by the rise of populism, the illiberal drift of the Hungarian and Polish governments has caused the first use of the new procedures, highlighting their insufficiency in the face of a crisis of this nature and showing the limits of the Unión's ability to exert its influence after accession.
\end{abstract}

\section{Keywords}

European integration; Rule of law; fifth enlargement; Poland; Hungary. 


\section{SUMARIO}

I. INTRODUCCIÓN. SOBRE LA CAPACIDAD DE LA UNIÓN PARA EJERCER SU INFLUENCIA ANTES Y DESPUÉS DE LA ADHESIÓN. II. EL DESARROLLO DE PROCEDIMIENTOS PARA SALVAGUARDAR LA DEMOCRACIA, LOS DERECHOS HUMANOS Y EL ESTADO DE DERECHO EN EL CONTEXTO DE LA QUINTA AMPLIACIÓN: 1. El procedimiento sancionador del Tratado de Ámsterdam. 2. El procedimiento preventivo del Tratado de Niza. 3. El procedimiento de diálogo del marco del Estado de derecho. III. EL AUGE DEL NACIONALPOPULISMO EN HUNGRÍA Y POLONIA Y LA PUESTA A PRUEBA DE LOS NUEVOS PROCEDIMIENTOS: 1. Las instituciones europeas ante la crisis del estado de derecho en Hungría: 1.1. La persuasión política y la interposición de recursos de incumplimiento. 1.2. La activación del mecanismo preventivo. 2. Las instituciones europeas ante la crisis del Estado de derecho en Polonia: 2.1. El primer uso del marco del Estado de derecho y la activación del mecanismo preventivo. 2.2. La interposición de recursos de incumplimiento. IV. CONCLUSIONES. SOBRE LA INSUFICIENCIA DE LOS NUEVOS PROCEDIMIENTOS Y LOS LÍMITES DE LA CAPACIDAD DE INFLUENCIA DE LA UNIÓN. BIBLIOGRAFÍA. FUENTES PRIMARIAS.

\section{INTRODUCCIÓN. SOBRE LA CAPACIDAD DE LA UNIÓN PARA EJERCER SU INFLUENCIA ANTES Y DESPUÉS DE LA ADHESIÓN}

Este artículo aborda la crisis del Estado de derecho en Hungría y Polonia, situándola en el marco de la historia de la integración europea. A lo largo de setenta años el proceso de integración ha conocido una extraordinaria expansión de sus competencias y de sus Estados miembros. De los sucesivos procesos de ampliación, el quinto constituyó el mayor desafío, tanto por el número de Estados que habían de incorporarse como por la dimensión de la transformación política y económica requerida. La quinta ampliación fue también la de mayor valor simbólico pues sellaba el fin de la división de Europa durante la Guerra Fría. En mayo de 2004 se incorporaban a la Unión Europea Hungría, Polonia, la República Checa, Eslovaquia, Eslovenia, Estonia, Letonia y Lituania, así como Malta y Chipre. En enero 2007, en una segunda ronda, accedían Bulgaria y Rumanía.

Si bien cada ampliación ha dejado su huella en el proceso de integración, la adhesión de diez países de Europa Central y Oriental, junto con Malta y Chipre, presentó a la Unión la oportunidad de desarrollar todo un conjunto 
de instrumentos multifacéticos y transformó la ampliación en una de sus políticas más exitosas ${ }^{1}$. También impulsó el desarrollo de los estudios sobre la ampliación, que fue profundizando en el proceso de europeización y el impacto de la política de ampliación en los Estados candidatos. Asimismo, se ha prestado especial atención a la efectividad de la política de condicionalidad de la adhesión, en virtud de la cual la Unión proporciona incentivos externos para que el Gobierno del país candidato o el candidato potencial cumplan determinadas condiciones con el fin de avanzar en el proceso.

En 2004, Frank Schimmelfennig y Ulrich Sedelmeier señalaban que mediante la política de condicionalidad para la adhesión los países de Europa Central y Oriental habían experimentado un notable proceso de gobernanza externa $^{2}$. Su deseo de adherirse a la Unión Europea, junto con el volumen de la normativa que acompaña a la adhesión, permitieron a la Unión ejercer una influencia sin precedentes en la reestructuración de sus instituciones nacionales y en sus políticas públicas. Estos autores distinguían entre la condicionalidad del acervo, relativa a toda la normativa específica que el candidato debe incorporar, y la condicionalidad democrática, que se refiere al respeto a los principios políticos en los que se basa la Unión, los derechos humanos y la democracia liberal.

La literatura ha señalado que la condicionalidad de preadhesión (ex ante) fue muy eficaz, particularmente en lo referente al acervo, habiendo impulsado con éxito la alineación de los países poscomunistas con la legislación de la Unión Europea ${ }^{3}$. También la condicionalidad democrática tuvo un efecto relevante, a pesar de que en este ámbito la Unión carecía de una legislación específica que desarrollase sus principios fundamentales y pudiese guiar las reformas internas ${ }^{4}$. Se ha señalado también que esta condicionalidad dependió en gran medida de las circunstancias iniciales del Estado candidato; en los casos de Hungría y Polonia, así como en la República Checa, el efecto de la condicionalidad democrática fue más reducido, pues el proceso de consolidación democrática ya estaba en marcha y "probablemente habría continuado por ese camino incluso en ausencia de la condicionalidad de la UE».

Siendo la perspectiva de la adhesión el incentivo principal de los candidatos y excluyéndose, salvo en los casos de Rumanía y Bulgaria, mecanismo

\section{Gateva (2018): 1.}

2 Schimmelfennig y Sedelmeier (2004): 669.

3 Sedelmeier (2008): 806; Epstein y Sedelmeier (2008), y Börzel y Schimmelfennig (2017).

$4 \quad$ Ibid.: 281.

5 Schimmelfennig y Sedelmeier (2004): 677. Traducción propia, al igual que las que siguen. 
alguno de condicionalidad tras la adhesión $(e x p o s t)^{6}$, podía temerse que la influencia de la Unión decreciese en los Estados de Europa Central y Oriental una vez que estos se convirtiesen en miembros de pleno derecho. Los procesos internos de europeización podrían debilitarse una vez que los elementos más fuertes de la condicionalidad desapareciesen?

En lo que respecta al acervo, la Unión afrontaba el reto mejor equipada pues contaba con instrumentos adecuados para supervisar y sancionar los posibles incumplimientos. Además, los peores presagios no se materializaron pues los datos sobre infracciones mostraron que el nivel de cumplimiento de la legislación europea en los nuevos Estados fue inesperadamente bueno ${ }^{8}$.

Más allá del acervo, cabía temer por la capacidad de la Unión para ejercer su influencia en los nuevos Estados miembros en lo relativo a los principios de la democracia liberal y los derechos fundamentales. Aquí, en cambio, como se verá, la Unión ha carecido durante décadas de instrumentos adecuados para ejercer su influencia y responder a una eventual vulneración de estos principios por parte de los Estados miembros. Es posible este sea aún el caso en nuestros días.

A pesar de los avances logrados por los Estados de Europa Central y Oriental en términos de democracia y buen gobierno desde los noventa, la brecha existente entre los antiguos y los nuevos Estados miembros no ha desaparecido?. Diez años tras la quinta ampliación algunos estudios concluían que los efectos económicos habían tenido mayor alcance que los políticos y señalaban que todos los nuevos Estados miembros habían sufrido problemas serios con la consolidación democrática ${ }^{10}$. Pero ha sido quizás en los últimos años cuando, en mayor medida, los retrocesos democráticos en algunos Estados de Europa Central y Oriental «han arrojado sombras sobre el poder transformador de la Unión»" ${ }^{11}$. Como se ha señalado, la Comisión Europea (en adelante, Comisión) «ha encontrado cada vez más difícil afirmar su influencia en el entorno posterior a la adhesión y lucha por desarrollar instrumentos que

6 En los casos de Rumanía y Bulgaria se estableció un mecanismo de cooperación y verificación con el fin de monitorear su progreso tras la adhesión respecto al poder judicial y la lucha contra la corrupción. Eli Gateva (2013) ha explicado que la condicionalidad se deteriora tras la adhesión, pues a la ausencia de recompensas para avanzar en el proceso se une la ausencia de mecanismos «con dientes» para sancionar el incumplimiento de las condiciones, produciendo una estructura de incentivos muy débil.

Papadimitriou et al. (2017): 11; Gateva (2013).

Sedelmeier (2008).

9 Borzël y Schimmelfennig (2017).

10 Véase el monográfico coordinado por Epstein y Jacoby (2014): 12.

11 Borzël y Schimmelfennig (2017): 278 y Papadimitriou et al. (2017): 1. 
eviten más retrocesos de la democracia liberal en los Estados miembros de Europa Central y Oriental $»^{12}$.

Este artículo examinará, en primer lugar, el proceso de creación de nuevos procedimientos para salvaguardar los valores de la Unión: la democracia, el Estado de derecho y los derechos fundamentales. Se atenderá al contexto y a los documentos de las negociaciones en el marco de las cuales se establecieron, con el fin de valorar en qué medida su inclusión respondió a la necesidad de cubrir el vacío que dejaba el fin de la condicionalidad democrática tras la adhesión de los Estados de Europa Central y Oriental. La primera pregunta planteada es pues la siguiente: ¿En qué medida respondió el desarrollo de los nuevos procedimientos para salvaguardar los valores de la Unión a la inminencia de la quinta ampliación?

En segundo lugar, se abordarán los dos primeros y únicos casos en los que las instituciones europeas han hecho uso de los nuevos procedimientos, poniendo a prueba su eficacia. Desde la llegada al poder del partido Fidesz en Hungría en el año 2011, y del Partido Ley y Justicia (PiS, por sus siglas en polaco) en Polonia en 2015, estos Gobiernos han promovido medidas que han reforzado el poder ejecutivo y erosionado el principio de división de poderes. Se considerará, mediante un análisis de fuentes primarias, la respuesta de las instituciones a las sucesivas vulneraciones del Estado de derecho por parte de dichos Gobiernos. La segunda pregunta planteada es pues la siguiente: ¿Qué valoración merece la eficacia de los nuevos procedimientos, concebidos para salvaguardar los valores de la Unión, tras su puesta a prueba en Hungría y Polonia?

\section{EL DESARROLLO DE PROCEDIMIENTOS PARA SALVAGUARDAR LA DEMOCRACIA, LOS DERECHOS HUMANOS Y EL ESTADO DE DERECHO EN EL CONTEXTO DE LA QUINTA AMPLIACIÓN}

A pesar de que en sus primeras décadas la integración europea se centrase en la economía y sus principios no se recogiesen de modo explícito en los Tratados, estos han formado parte desde su origen de la identidad del proceso. La existencia de instituciones estables que garanticen la democracia, el Estado de derecho y los derechos fundamentales ha constituido siempre, de hecho, un requisito indispensable para la adhesión. La larga ausencia de España es una buena muestra de ello.

Cuando tras la caída del Muro de Berlín se fortaleció la dimensión política de la integración, el preámbulo del Tratado de Maastricht proclamó su

$12 \quad$ Ibid.: 11. 
adhesión a estos principios. Más tarde, con la reforma de Ámsterdam, y ya con la vista puesta en el horizonte de la quinta ampliación, harían al fin su aparición en el articulado del Tratado de la Unión Europea (en adelante TUE), cuyo artículo 2 dice asi ${ }^{13}$ : «La Unión se fundamenta en los valores de respeto a la dignidad humana, libertad, democracia, igualdad, Estado de derecho y respeto de los derechos humanos, incluidos los derechos de las personas pertenecientes a las minorías».

Estos valores tienen que ver con la propia naturaleza de la Unión Europea. Expresan la autocomprensión de Europa como una unión de democracias liberales ${ }^{14} \mathrm{y}$ sitúan a la persona en el centro de la construcción europea.

Los valores del artículo 2 son también los que deben respetar los candidatos a la adhesión, tal y como quedó formalizado en 1993 en el Consejo Europeo de Copenhague, que requería que los Estados estuviesen dotados de instituciones que garantizasen la democracia, el imperio de la ley, los derechos humanos y la protección y el respeto de las minorías. Como se ha señalado, antes y durante las negociaciones de adhesión la condicionalidad tuvo un impacto positivo en la consolidación de las nuevas democracias de Europa Central y Oriental y permitió a la Unión ejercer una influencia sin precedentes en la reestructuración de sus instituciones.

Sin embargo, una vez que se formaliza la adhesión, con la mencionada excepción de Rumanía y Bulgaria, los Estados miembros dejan de estar sometidos a un procedimiento regular de control en lo que respecta a estos valores. Es lo que en ocasiones se ha denominado la paradoja de Copenhague ${ }^{15}$, en virtud de la cual el cumplimiento de los valores en los que se basa la Unión está sujeto a un control regular solo hasta el momento en que se produce la adhesión. Durante muchos ańos las instituciones carecieron de mecanismo alguno que permitiese reaccionar si un Estado miembro vulneraba grave y persistentemente los valores de la Unión, o en caso de existir un riesgo claro de que tal cosa pudiese producirse. Esta ausencia solo comenzó a cubrirse con el Tratado de Ámsterdam.

\section{EL PROCEDIMIENTO SANCIONADOR DEL TRATADO DE ÁMSTERDAM}

En 1996 la Unión emprendía una nueva reforma con el objetivo de realizar los cambios que posibilitasen la quinta ampliación. La inesperada

13 Una modificación posterior elevó los principios a la categoría de valores.

14 Von Bogdandy y Ioannidis (2014): 21.

15 Discurso de Vivien Reding (2013b), comisaria de Justicia. 
desintegración de la Unión Soviética había producido un vuelco histórico, un verdadero cambio sistémico en los países de Europa Central y Oriental ${ }^{16}$. Precisamente Hungría y Polonia fueron los pioneros en el camino hacia la Unión. A ellos se aplicaría desde 1989 el programa de ayuda a la reconstrucción económica PHARE, al que se irían sumando los demás. En 1991 las Comunidades firmaban los primeros acuerdos de asociación con ambos países, que para entonces ya habían ingresado en el Consejo de Europa, así como con Checoslovaquia. En 1994, Hungría y Polonia fueron también los primeros en presentar formalmente sus candidaturas.

Debido a su dimensión, la quinta ampliación requería una reforma previa que abordase cuestiones como el sistema de voto en el Consejo o la composición de la Comisión. La imposibilidad de llegar a un acuerdo y su aplazamiento a una posterior reforma explican que las negociaciones se cerrasen con sabor amargo. Sin embargo, en Ámsterdam se acordaron cambios importantes, en particular los relacionados con los derechos fundamentales. Entre ellos hacía su aparición el nuevo procedimiento sancionador.

El Grupo de Reflexión presidido por Carlos Westendorp que preparó la Conferencia Intergubernamental de 1995 había propuesto la introducción de un procedimiento que pudiese llevar al Estado que incurriese en violación grave y reiterada de los derechos humanos o de los principios democráticos «hasta la suspensión de los derechos inherentes a su condición de miembro» ${ }^{17}$. El informe precisaba que, si bien la opinión mayoritaria estaba en favor su inclusión, algunos discrepaban señalando que los Gobiernos ya protegían estos derechos de forma adecuada. Entre los Estados que apoyaron expresamente su inclusión en sus contribuciones escritas estaban España e Italia, que habían de ejercer esos meses la Presidencia del Consejo, así como Bélgica y Austria ${ }^{18}$.

Del informe se desprende que el mecanismo sancionador estuvo relacionado desde su origen con la perspectiva de la ampliación. La referencia al mecanismo viene precedida de las siguientes palabras: «Es opinión generalizada en el seno del Grupo que, en la situación actual del proceso de integración europea, sobre todo ante la perspectiva de la ampliación, es urgente asegurar el pleno respeto de los Derechos Fundamentales, tanto en las relaciones de la Unión y los Estados miembros como entre estos y los individuos ${ }^{19}$.

16 Balázs (2009): 315.

17 Consejo de la Unión Europea (1995): 42.

18 El documento del Gobierno español mencionaba incluso la posibilidad de contemplar una expulsión (Ministerio de Asuntos Exteriores, : 86). Sobre la posición de estos cuatro Estados véase Sadurski (2010: 7).

19 Consejo de la Unión Europea (1995): 42. 
Como ha señalado Wojciech Sadurski, en la mente de los negociadores la vulneración de los valores europeos debió convertirse en una perspectiva probable en unos Estados cuyo pasado estaba «empañado por violaciones masivas y sistemáticas de los derechos humanos y estructuras notablemente antidemocráticas, y cuyo reciente entusiasmo por los derechos humanos y las prácticas democráticas podría haberse visto con cierto grado de desconfianza $»^{20}$.

De hecho, en las propuestas de Austria e Italia la nueva disposición se insertaba inmediatamente tras la relativa a las condiciones de adhesión. La lectura de los documentos preparatorios deja fuera de duda la relación entre el nuevo procedimiento y la quinta ampliación.

En lo que respecta a la sanción, en las negociaciones llegó a mencionarse la posibilidad de una expulsión, cosa que la mayoría descartó "por innecesaria, si la suspensión de los derechos surte los efectos deseados, o por los riegos que supondría poner en cuestión la irreversibilidad de la pertenencia a la Unión», una consideración razonable antes de la retirada británica.

Finalmente, la conferencia formalizó un mecanismo de dos fases: la primera permitiría la constatación de la violación y la segunda la adopción de sanciones. En la actualidad está recogido en el artículo 7.2. del TUE que dice así:

2. El Consejo Europeo, por unanimidad y a propuesta de un tercio de los Estados miembros o de la Comisión y previa aprobación del Parlamento Europeo, podrá constatar la existencia de una violación grave y persistente por parte de un Estado miembro de los valores contemplados en el artículo 2 tras invitar al Estado miembro de que se trate a que presente sus observaciones.

3. Cuando se haya efectuado la constatación contemplada en el apartado 2, el Consejo podrá decidir, por mayoría cualificada, que se suspendan determinados derechos derivados de la aplicación de los Tratados al Estado miembro de que se trate, incluidos los derechos de voto del representante del Gobierno de dicho Estado miembro en el Consejo [...].

Con vistas a considerar su aplicación en los casos de Hungría y Polonia conviene destacar tres elementos. En primer lugar, en las negociaciones se reiteró que el mecanismo fue concebido para circunstancias extremas ${ }^{21}$. No pretende resolver casos individuales de violación de los derechos fundamentales, para los

20 Sadurski (2010): 2. Este autor ha destacado la relación entre la perspectiva de la ampliación y el mecanismo sancionador.

21 Langrish (1998): 15. 
que existen procedimientos jurisdiccionales internos e internacionales, sino afrontar un problema sistemático, una violación grave y persistente de los valores comunes. Su objetivo era responder «a toda una actitud de los órganos de un Estado miembro envueltos en una involución democrática ${ }^{22}$.

En segundo lugar, el mecanismo no se limita al ámbito de aplicación del derecho de la Unión, sino que permite intervenir en caso de que la violación tenga lugar en uno de los ámbitos reservados a la acción autónoma de los Estados. Esto explica las reticencias que se manifestaron en las negociaciones $^{23}$, que nunca han desaparecido por completo. Para muchos esta era una cuestión meramente nacional. Solo progresivamente el respeto a los valores comunes, también en los ámbitos de competencia nacional, se ha ido consolidando como un legítimo interés de la Unión.

En tercer lugar, teniendo en cuenta dichas reticencias no es de extrañar que se acordase que la constatación de la vulneración requiere la unanimidad del Consejo Europeo, excluido el Estado afectado, lo que en la práctica hace su uso muy improbable ${ }^{24}$. Una vez constatada la vulneración, el establecimiento de sanciones corresponde al Consejo por mayoría cualificada. El Tratado le otorga un amplio margen de libertad de apreciación política, dejando lugar para que una solución diplomática pueda remediar la situación. En cuanto a la sanción, se prevé la suspensión de determinados derechos incluido el voto, pero no se contempla la posibilidad de una expulsión.

\section{EL PROCEDIMIENTO PREVENTIVO DEL TRATADO DE NIZA}

En diciembre del año 2000, la Conferencia de Niza lograba por fin un acuerdo sobre la reforma institucional abriendo la puerta a la quinta ampliación. La reforma permitió también que se modificasen otras disposiciones del Tratado, entre las que se encontraba la relativa al procedimiento sancionador.

22 Mangas Martín (1998): 47.

23 Sobre las reticencias de los Gobiernos véase: Consejo de la Unión Europea (1995): 22. Las reticencias en el Parlamento Europeo se expresaron contundentemente en el debate que dio lugar a su Resolución de 2004 sobre la Comunicación de la Comisión. El Informe de la Comisión de Asuntos Constitucionales mencionaba «el riesgo de abuso político». Más crítica fue la opinión de la Comisión de Asuntos Jurídicos y Mercado Interior que afirmaba que la comunicación de la Comisión no era ni «necesaria ni oportuna» (Parlamento Europeo, 2004a: 13,16).

24 La constatación de la vulneración no recae en el Tribunal de Justicia, a pesar de la opinión de la Comisión Europea (Pérez González, 1998: 158). 
El objetivo consistía en añadir un segundo procedimiento, esta vez de carácter preventivo, que pudiera incoarse de existir un riesgo de violación grave de los valores comunes. La necesidad de contar con un mecanismo de esta naturaleza se puso de manifiesto como consecuencia de los hechos ocurridos en Austria en el año 2000 cuando por vez primera se planteó seriamente la posibilidad de hacer uso del artículo 7. La ironía de que el Estado en cuestión fuese una consolidada democracia en lugar de un Estado poscomunista de la quinta ampliación no ha pasado desapercibida ${ }^{25}$.

La crisis se inició cuando el partido conservador austriaco formó un Gobierno de coalición con el FPÖ, un partido que se había distinguido por sus posiciones xenófobas y extremistas. Con el fin de manifestar su repulsa, los catorce socios de Austria en la Unión impusieron medidas diplomáticas de carácter bilateral tales como la no recepción de sus embajadores o la negativa a apoyar a los candidatos propuestos por Austria en organismos internacionales. Si bien fueron los Estados, no la Unión, los que coordinadamente impusieron tales medidas, "Austria se convirtió, de facto, de la noche a la mañana, en un paria en la Unión Europea» ${ }^{26}$.

No parecía posible, sin embargo, hacer uso del mecanismo sancionador, pues a pesar de que las declaraciones de los líderes del FPÖ y en particular de Jörg Haider hicieran temer que el Gobierno adoptase medidas contrarias a los derechos fundamentales, lo cierto es que no se había producido una violación clara y persistente de los valores de la Unión. De hecho, la firmeza de la reacción europea fue tal que algunos se han planteado si estas medidas se hubiesen adoptado en ausencia de ciertas consideraciones de política interna en algunos Estados $^{27}$. Mediante estas sanciones los catorce dirigían un mensaje a los candidatos, «una declaración sobre los límites de lo que es política e ideológicamente aceptable en la Unión, sobre los límites de la diversidad, en vísperas de un fuerte aumento de la diversidad $»^{28}$.

En julio de 2000, los catorce Estados miembros solicitaban la elaboración de un informe sobre el compromiso del Gobierno austriaco con los valores europeos y la naturaleza del FPÖ. El denominado «Informe de los tres sabios ${ }^{29}$ puso de manifiesto el compromiso del Gobierno austriaco con los valores comunes y recomendó levantar las medidas diplomáticas. Señalaba también que su mantenimiento podría resultar contraproducente y generar

\footnotetext{
De Burca (2004): 696; Sadurski (2010): 2.

Merlingen et al. (2001): 60.

Ibid.: 74.

Sadurski (2010): 18.

Athisaari et al. (2000).
} 
sentimientos nacionalistas, una consideración bien presente en la actualidad en relación los casos polaco y húngaro.

Este episodio puso de manifiesto la necesidad de reformar el artículo 7 de manera que las instituciones pudiesen actuar no solo en el supuesto de que se constatase una violación grave y persistente de los valores europeos, sino también con carácter previo, cuando existiese un riesgo claro de que tal cosa se produjese. Activar un mecanismo de alerta parecía «más coherente que esperar a que se produjeran los actos de violación» ${ }^{30}$. La reforma de Niza incluyó en el artículo 7.1 el nuevo procedimiento preventivo:

A propuesta motivada de un tercio de los Estados miembros, del Parlamento Europeo o de la Comisión, el Consejo, por mayoría de cuatro quintos de sus miembros y previa aprobación del Parlamento Europeo, podrá constatar la existencia de un riesgo claro de violación grave por parte de un Estado miembro de los valores contemplados en el artículo 2 . Antes de proceder a esta constatación, el Consejo oirá al Estado miembro de que se trate y por el mismo procedimiento podrá dirigirle recomendaciones [...].

Con vistas al examen de los casos húngaro y polaco conviene destacar dos elementos. En primer lugar, en lo que respecta a las condiciones de aplicación, el procedimiento puede incoarse en caso de riesgo claro de violación grave, es decir, antes de que tal violación se materialice. Su objetivo consiste, precisamente, en evitar que se produzca. La Comisión ha señalado que el riesgo "pertenece aún al ámbito de la simple posibilidad, aunque haya que calificarlo: debe quedar "claro", excluyendo así los riesgos de carácter demasiado hipotéticos $»^{31}$. Este procedimiento es independiente del sancionador. Si bien parece razonable que le preceda, el Tratado no lo requiere. Pero, sobre todo, nos parece importante señalar que su objetivo era reforzar el sistema, no debilitarlo. El nuevo procedimiento no se incluyó con el fin de aplazar o sustituir el procedimiento sancionador.

En segundo lugar, en lo que atañe al procedimiento, cabe destacar el refuerzo del papel del Parlamento Europeo, que puede también iniciar el procedimiento. Se precisa a continuación la aprobación del Consejo por mayoría de cuatro quintos y del Parlamento Europeo. El umbral en el Consejo es alto, si bien no es necesario alcanzar la unanimidad que sí se exige en el procedimiento sancionador. De nuevo, el Consejo tiene libertad de apreciación a la hora de constatar el riesgo de violación; se trata, pues, de un mecanismo de

30 Oreja Aguirre (2019): 5.

31 Comisión Europea (2003): 8. 
carácter político, lo que deja lugar a una solución diplomática ${ }^{32}$. La consecuencia última consiste, tan solo, en la dirección de recomendaciones al Estado miembro.

El nuevo mecanismo preventivo entró en vigor en febrero de 2003. A finales de año, a pocos meses de culminar la ampliación, la Comisión detallaba en una comunicación las condiciones de aplicación del artículo 7. Entre los factores que explicaban su necesidad, señalaba expresamente, en primer lugar, la inminencia de la ampliación: «En el momento en que la Unión inicia una nueva etapa de su desarrollo que se caracteriza por la inminencia de una ampliación que supondrá una mayor diversidad cultural, social y política entre los Estados miembros, parece oportuno que las instituciones profundicen en su enfoque común en cuanto a la defensa de los valores de la Unión »33.

Precisamente en ese momento, nada menos que seis años después de que el mecanismo sancionador entrase en escena con la reforma de Ámsterdam, la Comisión anunciaba su «intención de ejercer plenamente y con el máximo sentido de responsabilidad» las prerrogativas que le otorgaba el artículo 7 , cuyas condiciones de aplicación solo ahora procedía a concretar. La evidente relación entre la inminente ampliación y el énfasis en el artículo 7 no debió pasar desapercibida al Parlamento Europeo, que quiso subrayar el principio de igualdad de trato de todos los Estados miembros, «sin distinción de tamaño, orientación política, contribución financiera al presupuesto de la Unión, antigüedad como Estado miembro u otras diferencias" "34. El artículo 7 cobraba protagonismo ante la inminente adhesión de los nuevos Estados.

\section{EL PROCEDIMIENTO DE DIÁLOGO DEL MARCO DEL ESTADO DE DERECHO}

Transcurridos unos años desde la quinta ampliación, en un tiempo en el que se sufrían las consecuencias de la crisis económica y financiera, las instituciones europeas comenzaron a manifestar su inquietud por ciertos acontecimientos que revelaban una quiebra de sus valores y, en particular, del Estado de derecho. En 2013 la Comisión contemplaba con preocupación tres asuntos: las expulsiones colectivas de ciudadanos romanís que tuvieron lugar en Francia en el verano de 2010; el cuestionamiento de la independencia del Poder

\footnotetext{
32 El Tribunal de Justicia no podrá ejercer un control jurisdiccional sobre la constatación del riesgo a pesar de que la Comisión había solicitado de nuevo una mayor implicación del Tribunal.

33 Comisión Europea (2003): 4.

34 Parlamento Europeo (2004b): 410.
} 
Judicial en Hungría desde finales de 2011, y el incumplimiento de las sentencias del Tribunal Constitucional en Rumanía en 2012 $2^{35}$. Dos de los tres casos afectaban a Estados de la quinta ampliación.

En ninguno de ellos, sin embargo, se hizo uso del artículo 7. Desde la Comisión se señalaba que los altos umbrales requeridos hacían "casi imposible» su uso ${ }^{36}$. Por ello se reclamaban mecanismos más flexibles, capaces de llenar el vacío entre "la mano suave de la persuasión política y la mano dura del artículo 7 del Tratado» ${ }^{37}$.

En 2013 la Comisión daba un primer paso mediante la adopción del Cuadro de Indicadores de la Justicia en la $\mathrm{UE}^{38}$, un instrumento concebido para realizar un examen comparativo de independencia, calidad y eficiencia judicial. En 2014 daba un paso más estableciendo en una comunicación ${ }^{39}$ un nuevo procedimiento denominado Marco del Estado de Derecho, con el fin de resolver situaciones en las que existiese una amenaza sistémica antes de que se diesen las condiciones para activar el artículo 7. Algo así como a un mecanismo previo al mecanismo preventivo, referido de modo específico al Estado de derecho. El proceso constaría de tres fases, una evaluación por parte de la Comisión, una recomendación que identificaría los problemas en cuestión y daría al Estado un plazo para su resolución, y un seguimiento.

Con vistas al posterior examen de los casos húngaro y polaco conviene destacar dos elementos. En primer lugar, la Comisión ofrece una aproximación conceptual al Estado de derecho, cuya categorización resulta particularmente difícil. El Estado de derecho es un principio que afecta al ejercicio de los poderes públicos pues garantiza que estos actúan dentro de los límites fijados por la ley y bajo el control de órganos jurisdiccionales independientes. En los ordenamientos jurídicos europeos cabe distinguir entre una acepción más formal, que pone el acento en los elementos procedimentales como la independencia judicial o la tutela judicial efectiva, frente a otra más sustantiva, vinculada a la protección de los derechos fundamentales ${ }^{40}$. La Comisión se decanta por una acepción amplia, que incorpora elementos de carácter sustantivo, afirmando que el Estado de derecho constituye «el vehículo que garantiza el cumplimiento y el respeto de la democracia y los

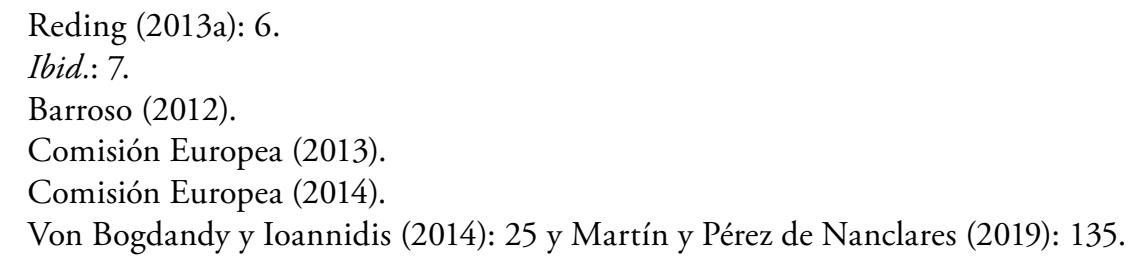


derechos humanos» ${ }^{41}$. La Comisión incide en que no puede haber respeto de los derechos fundamentales y democracia si no hay Estado de derecho pues «los derechos fundamentales solo son eficaces si son justiciables» y la democracia solo está protegida si el poder judicial, incluidos los tribunales constitucionales, "pueden garantizar la libertad de expresión, la libertad de reunión y el respeto de las normas que regulan el proceso político y electoral» ${ }^{42}$.

El contenido preciso de los principios y normas en los que se concreta el Estado de derecho varía en los sistemas constitucionales de los Estados miembros. No obstante, la Comisión destaca una lista no exhaustiva que incluye la legalidad, la seguridad jurídica, la prohibición de arbitrariedad de los poderes ejecutivos, la igualdad ante la ley, así como «unos tribunales independientes e imparciales».

En segundo lugar, el Marco no es una alternativa, sino un mecanismo que complementa y precede el artículo 7 , una suerte de antesala ${ }^{43}$. La Comisión incidía en que su objetivo es encontrar una solución con el Estado en cuestión y prevenir la aparición de una amenaza sistémica que pudiese convertirse en "un riesgo claro de violación grave» en el sentido del artículo 7. Se activará cuando las autoridades «estén adoptando o tolerando situaciones que puedan afectar sistemática y negativamente a la integridad, estabilidad o el buen funcionamiento de las instituciones y los mecanismos de salvaguardia establecidos a nivel nacional para garantizar el Estado de derecho».

$\mathrm{Ni}$ que decir tiene que en la práctica no resultará sencillo distinguir la situación contemplada en el Marco — indicio claro de amenaza sistémica para el Estado de derecho- de aquella contemplada en el mecanismo preventivo —riesgo claro de vulneración del Estado de derecho-. Con razón se ha señalado que en el desarrollo de los mecanismos para salvaguardar los valores europeos se ha producido una suerte de pragmatismo invertido en virtud del cual «se han ido ańadiendo mecanismos más propios del soft law a medida que se producían amenazas más claras al Estado de derecho, en lugar de aplicar los mecanismos más drásticos que ya existían ${ }^{44}$.

41 Sigue así la estela marcada por el Tribunal de Justicia y el Consejo de Europa, cuyo Tribunal Europeo de Derechos Humanos y cuya Comisión de Venecia han contribuido a definir este concepto.

42 Comisión Europea (2014): 4, 5.

43 Mangas Martín (2018): 2.

44 Blázquez (2019): 22. 


\section{EL AUGE DEL NACIONAL - POPULISMO EN HUNGRÍA Y POLONIA Y LA PUESTA A PRUEBA DE LOS NUEVOS PROCEDIMIENTOS}

Concebidos «para amagar más que para dar»" ${ }^{45}$, los nuevos procedimientos podrían haber tenido un carácter meramente disuasorio. Sin embargo, en los últimos años los valores europeos se han visto gravemente amenazados como consecuencia del auge de los populismos y la erosión de las democracias liberales, otorgándoles una relevancia nueva.

Si bien el populismo no es un fenómeno novedoso, ha merecido especial atención en Europa en los años posteriores a la crisis económica y financiera, con cuyos efectos a menudo se asocia. No es este el lugar para profundizar sobre sus causas, que algunos atribuyen primordialmente a factores socioeconómicos relacionados con una creciente desigualdad y otros a factores culturales que tienen que ver con la inseguridad e incertidumbre propias de nuestro tiempo y con el rápido cambio de los valores sociales ${ }^{46}$.

El populismo se caracteriza frecuentemente por la oposición entre la élite y el pueblo. Diferencia dos grupos homogéneos y antagónicos, un pueblo puro, que dice representar, y una élite corrupta a la que quiere desplazar del poder ${ }^{47}$. Podría considerarse una ideología ligera, compatible con otra más consistente que pudiera ser tanto de derechas como de izquierdas. También se ha caracterizado el populismo como una forma de retórica con dos postulados: en primer lugar, se cuestiona la legitimidad del establishment (políticos electos, partidos, intelectuales, expertos, multinacionales, medios, jueces...) y, en segundo lugar, se enfatiza que la autoridad política legítima se basa en la soberanía popular y en la regla mayoritaria y se apela a la voz directa del pueblo mediante elecciones, referéndums y manifestaciones ${ }^{48}$. Cabe mencionar que entre los representantes de ese establishment cuestionado suele ocupar un lugar muy especial la Unión Europea. Otros consideran que lo propio del populismo es la afirmación de que solo ellos representan a los ciudadanos, a la gente real, a la mayoría silenciosa. Se consideran los únicos representantes del pueblo y al negar la legitimidad del resto de contendientes atacan el principio de pluralidad política que caracteriza las democracias liberales ${ }^{49}$.

El auge del populismo se ha dejado sentir con fuerza en los últimos años en los países de Europa Central y Oriental y constituye una característica

\footnotetext{
45 Martín y Pérez de Nanclares (2019): 152.

46 Inglehart y Norris (2016).

47 Mudde y Kaltwasser (2017).

48 Norris e Inglehart (2019).

49 Müller (2017).
} 
esencial de los partidos de extrema derecha en Hungría y Polonia. Ricardo Martín de la Guardia y Guillermo Pérez Sánchez han destacado tres rasgos pronunciados que caracterizan a estos partidos que denominan nacionalpopulistas $^{50}$. El primero de ellos es el nativismo, que sostiene que el Estado debería velar por el mantenimiento de la homogeneidad nacional para evitar la pérdida de valores considerados propios frente a los foráneos. El segundo es el autoritarismo, que aboga por mantener como bien supremo el orden social y enfatiza la dirección de líderes fuertes y carismáticos. El tercero es el populismo, que divide a la sociedad en pueblo y élite y constituye, en su opinión, la característica esencial de los partidos de extrema derecha en estos países.

Estos autores seńalan también la particularidad de estos movimientos en Europa Central y Oriental. Consideran que constituyen un caso diferenciado, derivado de su historia reciente, tras décadas de socialismo real y singulares transiciones a la democracia. En su opinión, la idealización de determinados momentos de la historia constituye una clave mucho más relevante de su discurso que en los partidos nacionalpopulistas de Europa Occidental: «En el Oeste, los partidos de esta familia ideológica están más preocupados por la inmigración y la seguridad mientras que, si bien estas mismas inquietudes son compartidas en los casos de Hungría y Polonia, en estos dos últimos países prestan mucha más atención a cuestiones como el irredentismo, la identificación con los valores religiosos y la homogeneidad étnica ${ }^{51}$.

Desde la llegada al poder del partido Fidesz en Hungría y de Justicia y Libertad en Polonia estos Gobiernos han promovido medidas que han reforzado el poder ejecutivo y erosionado la división de poderes. Werner Müller ha señalado que ambos casos responden al patrón distintivo de gobernación autoritaria que caracteriza a los populistas cuando alcanzan el poder. En su opinión, estos tratan de colonizar u «ocupar» las estructuras del Estado, colocando a sus leales en puestos burocráticos que no deberían ser partidistas. Müller señala que ambos Gobiernos, una vez llegados al poder, se movieron deprisa para eliminar la independencia del poder judicial. También apunta a la captación de los líderes de los medios de comunicación y la actitud dura hacia las organizaciones no gubernamentales y otros actores críticos de la sociedad civili52.

En esta deriva, los Gobiernos de Polonia y Hungría han puesto en jaque los valores europeos, provocando la crisis del Estado de derecho más grave que

\footnotetext{
50 Martín de la Guardia y Pérez Sánchez (2019): 180.

51 Idem. También Péter Balázs (2009) ha señalado las razones que explican el resurgimiento en Europa Central y Oriental de sentimientos nacionalistas por largo tiempo reprimidos y su relación con la integración europea.

52 Müller (2017): 12.
} 
ha atravesado nunca la Unión Europea ${ }^{53}$. Al final, «el temor se ha hecho realidad ${ }^{54}$. El Estado de derecho ha sido efectivamente amenazado y los procedimientos desarrollados para salvaguardar los valores europeos han sido empleados por vez primera, poniéndose a prueba su eficacia.

\section{LAS INSTITUCIONES EUROPEAS ANTE LA CRISIS DEL ESTADO DE DERECHO EN HUNGRÍA}

Pocos meses tras el nombramiento del primer ministro, Viktor Orban, al frente de una coalición respaldada por una mayoría de dos tercios en el Parlamento, el presidente de la Comisión señalaba su inquietud por la Ley de Medios de Comunicación promovida por el nuevo Gobierno, subrayando el valor de la libertad de prensa y del pluralismo de los medios en la Unión Europea ${ }^{55}$.

En los meses siguientes el Gobierno impulsó una reforma de la Constitución, así como una serie de leyes cardinales que despertaron las alarmas en diversos organismos internacionales. En el mes de junio, un informe de la Comisión de Venecia (órgano consultivo del Consejo de Europa) se refería al proceso de reforma constitucional censurando la ausencia de debate público y de diálogo con la oposición. Señalaba también el número de asuntos regulados en las leyes cardinales, una práctica que dificultaría su posterior reforma, al requerir una mayoría de dos tercios en lugar de una mayoría simple. El informe señalaba que las políticas culturales, religiosas, socioeconómicas o financieras no deberían regularse mediante leyes cardinales, sino dejarse al proceso político ordinario ${ }^{56}$.

\subsection{La persuasión política y la interposición de recursos de incumplimiento}

A inicios de 2012 la Comisión manifestaba su inquietud respecto a una serie de nuevas medidas que afectaban a la independencia de instituciones y tribunales. Especial preocupación causaban tres asuntos: la independencia del banco central nacional; la independencia de la autoridad de protección de datos, y las medidas relativas al Poder Judicial, que anticipaban drásticamente la edad de jubilación de los jueces a la edad de 62 años $^{57}$.

\footnotetext{
53 Kochenov (2019): 424.

54 Pérez de Nanclares (2019): 152.

55 Barroso (2011).

56 Comisión de Venecia (2011): 28-29.

57 Comisión Europea (2012).
} 
En los meses siguientes la Comisión interpuso dos recursos de incumplimiento contra sendas medidas que, además de vulnerar el Estado de derecho, quebrantaban disposiciones concretas del ordenamiento jurídico de la Unión. En el primer caso, la reducción de la edad de jubilación vulneraba la directiva de igualdad de trato ${ }^{58}$, constituyendo una discriminación por motivos de edad. En el segundo, al poner fin prematuramente al mandato de la autoridad de protección de datos, se vulneraba la legislación europea relativa a esta cuestión ${ }^{59}$. En ambos asuntos, el Tribunal de Justicia respaldó a la Comisión, declarando el incumplimiento ${ }^{60}$.

La presión pareció provocar un cambio de rumbo y una parte de las leyes cardinales fue derogada. Sin embargo, en marzo de 2013 el Parlamento húngaro adoptaba una Cuarta Enmienda a la Ley Fundamental que fue inmediatamente contestada. Un nuevo informe de la Comisión de Venecia declaraba que socavaba gravemente la posibilidad de revisión constitucional y ponía en peligro el sistema de controles y equilibrios, teniendo por efecto perpetuar las elecciones hechas por la mayoría actual. Concluía el informe que «La Cuarta Enmienda es el resultado de una visión instrumental de la Constitución como un medio político de la mayoría gubernamental ${ }^{61}$.

La tensión entre el Gobierno húngaro y las instituciones europeas no cesó. Así lo demuestra la campaña emprendida por las autoridades húngaras en el otońo de 2016, con motivo de la consulta nacional relativa a la inmigración, a la que denominaron «Stop Bruselas». También generó una fuerte tensión política el debate promovido sobre el establecimiento de la pena de muerte.

Los motivos que han suscitado en los últimos años la preocupación de las instituciones europeas han sido muy diversos. El Parlamento Europeo ha censurado los ataques contra las organizaciones de la sociedad civil, los derechos de los solicitantes de asilo, el pluralismo de los medios de comunicación, los derechos de la población romaníí ${ }^{62} \ldots$ Entre los últimos acontecimientos ha destacado el «Proyecto de Ley sobre la transparencia de las organizaciones que reciben financiación extranjera» y la modificación de la "Ley sobre la Educación Superior Nacional», que ha constituido una amenaza directa para la

58 Directiva 2000/78/CE, relativa a la igualdad de trato en el empleo y la ocupación.

59 Directiva 95/46/CE relativa a la protección de datos.

60 Sentencia del Tribunal de Justicia, Comisión contra Hungría, asunto C-286/12, ECLI:EU:C:2012:687. Sentencia del Tribunal de Justicia, Comisión contra Hungría, asunto C-288/12, ECLI:EU:C:2014:237.

61 Comisión de Venecia (2013)

62 Parlamento Europeo (2017a). 
Universidad Centroeuropea, un centro que ofrece titulaciones reconocidas en los Estados Unidos, y que finalmente, debido a la presión del Gobierno, se ha visto obligado a abandonar Budapest y trasladar su sede a Viena.

En 2017 la Comisión interpuso dos nuevos recursos de incumplimiento contra Hungría, el primero sobre la legislación que afecta a la Universidad Centroeuropea y el segundo sobre la legislación relativa a la financiación de las organizaciones no gubernamentales ${ }^{63}$. Ambos asuntos están pendientes de resolución.

\subsection{La activación del mecanismo preventivo}

A lo largo de este proceso la Comisión no ha hecho uso del Marco del Estado de Derecho, a pesar de que su establecimiento fue en gran medida una respuesta a la crisis húngara. Tampoco ha activado los mecanismos preventivo y sancionador del artículo 7, lo que le ha costado duras críticas de la doctrina. Algunos han apuntado que la pertenencia de Orban al Partido Popular Europeo le ha proporcionado amparo ${ }^{64}$, lo que podría explicar en parte las reticencias de la Comisión. Otros han señalado que, si bien Hungría ha llevado la delantera en la deriva iliberal, generando un efecto arrastre en Polonia, en comparativa, el caso polaco resulta más preocupante ${ }^{65}$.

Finalmente, ha sido el Parlamento Europeo el que ha tomado la iniciativa. En su Resolución de septiembre de $2018^{66}$ señalaba que, si bien las autoridades húngaras siempre habían estado dispuestas a debatir sobre la legalidad de las medidas, no habían hecho frente a la situación y señalaba toda una serie de asuntos preocupantes:

El funcionamiento del sistema constitucional y electoral; la independencia del poder judicial y de otras instituciones y los derechos de los jueces; la corrupción y los conflictos de intereses; la protección de datos y de la intimidad; la libertad de expresión; la libertad de cátedra; la libertad de religión; la libertad de asociación; el derecho a la igualdad de trato; los derechos de las personas pertenecientes a minorías, incluida la población romaní y los judíos, así como la

63 Tribunal de Justicia, asunto C-66/18, DO C 211, de 18.6.2018, p. 7; asunto C-78/18, DO C 211, de 18.6.2018, p. 8.

64 Müller (2017): 9 y Pech y Scheppele (2017): 39.

65 Pérez Bernárdez (2016): 68. Sobre las razones por las que la Comisión actuó frente a Polonia y no contra Hungría, en particular Closa (2019).

66 Parlamento Europeo (2018). 
protección frente a los mensajes de odio contra esas minorías; los derechos fundamentales de los migrantes, solicitantes de asilo y refugiados y los derechos económicos y sociales.

En vista de todo ello, el Parlamento activaba el procedimiento preventivo, solicitando al Consejo la constatación de la existencia de un riesgo claro de violación grave de los valores en los que se fundamenta la Unión. Una vez activado, el procedimiento quedó pendiente de una decisión del Consejo que a día de hoy aún no se ha adoptado a pesar de que, como se ha señalado, el procedimiento preventivo no requiere unanimidad. Conviene notar que a pesar de que a estas alturas difícilmente pueda ponerse en duda la existencia de una violación grave y persistente del Estado de derecho, no se ha planteado la activación del mecanismo sancionador.

\section{LAS INSTITUCIONES EUROPEAS ANTE LA CRISIS DEL ESTADO DE DERECHO EN POLONIA}

La deriva polaca se inició en octubre de 2015 tras la victoria electoral del partido Ley y Justicia de Jaroslaw Kaczynski. Siguiendo la estela del Gobierno húngaro, el polaco adoptó sin dilación medidas controvertidas que afectaban a la independencia del Poder Judicial y a los medios de comunicación.

En el mes de diciembre el Tribunal Constitucional dictó dos sentencias en relación con las primeras medidas adoptadas por el Gobierno, relativas a su composición, que permitían anular nombramientos judiciales de la anterior legislatura y reducían la duración de los mandatos de su presidente y vicepresidente. El Gobierno reaccionó impidiendo la ejecución de estas sentencias. Unos días después el Parlamento polaco modificaba la Ley del Tribunal Constitucional, afectando a su funcionamiento y a la independencia de sus jueces. La Comisión manifestó de inmediato su preocupación sobre esta cuestión, así como sobre la nueva legislación relativa a los medios de comunicación, que afectaba a los consejos de administración y supervisión de la radio y la televisión pública.

2.1. El primer uso del Marco del Estado de Derecho y la activación del mecanismo preventivo

En enero de 2016, transcurridos apenas tres meses desde la formación del Gobierno, la Comisión recurría por vez primera al Marco del Estado de 
Derecho mediante el envío de una carta al Gobierno polaco. Mientras, el Tribunal Constitucional consideraba que la controvertida ley de diciembre era inconstitucional, a lo que el Gobierno reaccionaba negándose a publicar la sentencia. También la Comisión de Venecia reaccionaba aprobando un contundente dictamen que señalaba que mientras el Tribunal Constitucional no pudiese llevar a cabo su labor de manera eficiente, no solo estaría en peligro el Estado de derecho, sino también la democracia y los derechos humanos ${ }^{67}$.

En este contexto, habiendo recibido el respaldo del Parlamento Europeo ${ }^{68}$, la Comisión dirigía a Polonia su primera recomendación ${ }^{69}$, en la que afirmaba la existencia de una amenaza sistémica para el Estado de derecho y recomendaba medidas que incluían la publicación y ejecución de las mencionadas sentencias del Constitucional, instando al Gobierno polaco a que tomase medidas en un plazo de tres meses.

Insatisfecha con su reacción, y habiendo aprobado el Parlamento Europeo una nueva resolución ${ }^{70}$, la Comisión adoptaba su segunda recomendación ${ }^{71}$ relativa al Tribunal Constitucional. Además de los asuntos señalados, manifestaba su preocupación por tres nuevas leyes relativas al estatuto de los jueces, a los procedimientos disciplinarios, a la jubilación anticipada y a la organización del Tribunal. La Comisión alertaba sobre el «frenesí legislativo» que había dado lugar a la aprobación de nada menos que seis normas relativas al Tribunal Constitucional en el espacio de un año, normas cuyo efecto combinado le impediría al Tribunal desempeñar un control efectivo, e instaba a las autoridades polacas a resolver los problemas en el plazo de dos meses.

Lejos de ceder en sus pretensiones, el Gobierno mantuvo su presión sobre el Tribunal Constitucional e impulsó en 2017 un segundo asalto a la independencia del Poder Judicial. Esta vez las cuatro nuevas normas afectaban al Tribunal Supremo, al Consejo Nacional del Poder Judicial, a la Organización de los Tribunales Ordinarios y a la Escuela Nacional de la Judicatura. Diversos organismos internacionales expresaron su profunda preocupación sobre estas normas, cuya combinación tendría por efecto socavar estructuralmente la independencia del Poder Judicial polaco ${ }^{72}$. Especialmente contundente fue

\footnotetext{
Comisión de Venecia (2016).

Parlamento Europeo (2016a).

Comisión Europea (2016a).

Parlamento Europeo (2016b)

Comisión Europea (2016b).

Entre ellas, la Red de Presidentes de Tribunales Supremos de la Unión Europea (declaración abril de 2017 relativa a Polonia: https://bit.ly/2I4WGDr) y la Red
} 
la Comisión de Venecia, que señaló que las nuevas normas permitirían que los poderes legislativo y ejecutivo interfiriesen «de manera severa y extensa en la Administración de justicia» ${ }^{73}$. Especial preocupación causaba la disminución de la edad de jubilación de los jueces del Supremo, que podría tener por efecto que cerca del $40 \%$ de los mismos abandonasen el Tribunal y fuesen reemplazados por nuevos jueces nombrados por recomendación del recién compuesto Consejo General del Poder Judicial, previsiblemente dominado por los nombramientos políticos de la mayoría gobernante. Varias organizaciones no gubernamentales manifestaron también su alarma y solicitaron la apertura del procedimiento del artículo $7^{74}$.

Como consecuencia de ello, la Comisión adoptaba una tercera recomendación ${ }^{75}$ en la que instaba a las autoridades polacas a resolver estos problemas en el plazo de un mes, insistiendo en que no adoptasen medida alguna para jubilar forzosamente a los jueces del Tribunal Supremo. El presidente Jean Claude Juncker señaló que la Unión no podía aceptar un sistema que permitiese «cesar a los jueces a voluntad». También el comisario Franz Timmermans señalaba que las leyes en cuestión «abolirían cualquier independencia judicial restante y pondrían al poder judicial bajo el control político total del Gobierno ${ }^{76}$. De tomarse alguna medida de ese tipo, la Comisión anunciaba que pondría en marcha inmediatamente el procedimiento preventivo del artículo 7, pero tampoco esto tuvo las consecuencias esperadas.

Tras una nueva resolución del Parlamento Europeo ${ }^{77}$, la Comisión adoptaba su cuarta recomendación ${ }^{78}$. Señalaba de nuevo la reducción de la edad de jubilación de los jueces del Supremo, el poder discrecional del presidente para prolongar su mandato y el nuevo procedimiento de recurso extraordinario, que preveía incluso la posibilidad de cuestionar sentencias definitivas dictadas varios años antes. Acto seguido, sin esperar la respuesta de las autoridades polacas, procedía por fin a iniciar el procedimiento preventivo del artículo

Europea de Consejos del Poder Judicial (declaraciones de 2017 relativas a Polonia: https://www.encj.eu/articles/96).

73 Comisión de Venecia (2017).

74 Véase la Carta abierta dirigida al colegio de comisarios de 16 de febrero de 2017 firmada inicialmente por Amnistía Internacional, FIDH, Human Rights Watch, Open Society European Policy Institute y Periodistas sin Fronteras. Posteriormente se adhirieron numerosas ONGs. Disponible en: https://bit.ly/3m6YICt

75 Comisión Europea (2017a).

76 Timmermans (2017).

77 Parlamento Europeo (2017b).

78 Comisión Europea (2017b). 
$7^{79}$. Respondía así a las voces que le instaban a actuar y criticaban que el prolongado diálogo mantenido con las autoridades polacas, lejos de revertir la situación, les había dado tiempo "para consumar su estrategia política para poner fin al Estado de derecho» ${ }^{80}$.

La prensa se hizo eco de la noticia señalando, no sin cierto exceso, que la Comisión había activado «el botón nuclear», pues el procedimiento iniciado no era el sancionador, sino solamente el preventivo. En virtud del mismo, la Comisión invitaba al Consejo a determinar la existencia de un riesgo claro de violación grave del Estado de derecho y a dirigir a Polonia las recomendaciones adecuadas.

La propuesta motivada de la Comisión pone de manifiesto la distancia entre la gravedad de la situación y la afirmación de la existencia de un riesgo claro de violación grave, en virtud del cual la Comisión iniciaba el procedimiento preventivo en lugar del sancionador. En todo caso, la propuesta de la Comisión no ha dado lugar, hasta la fecha, a la adopción de medida alguna. Para prosperar precisa una mayoría de cuatro quintos en el Consejo y la aprobación del Parlamento Europeo. En todo caso, no daría lugar más que a la dirección de recomendaciones al Estado polaco.

\subsection{La interposición de recursos de incumplimiento}

Al margen de la activación de los mecanismos específicos analizados, la Comisión ha tratado de ejercer su influencia mediante dos cauces. En primer lugar, ha planteado la vinculación del presupuesto de la Unión al respeto al Estado de derecho, proponiendo un reglamento ${ }^{81}$ en virtud del cual una deficiencia generalizada del Estado de derecho como la puesta en peligro de la independencia del poder judicial podría dar lugar a la suspensión de los pagos y de los compromisos y a la reducción de la financiación. De adoptarse esta controvertida propuesta, el procedimiento previsto permitiría a la Comisión adoptar dichas medidas a menos que el Consejo decidiese, por mayoría cualificada, rechazar la propuesta en el plazo de un mes. Esta suerte de mayoría inversa fortalecería el papel de la Comisión y permitiría superar en el Consejo las dificultades derivadas de los altos umbrales del artículo 7.

\footnotetext{
79 Comisión Europea (2017c).

80 Mangas Martín (2018): 3.

81 Comisión Europea (2018). Sobre las últimas iniciativas de la Comisión véase también Comisión Europea (2019).
} 
En segundo lugar, la Comisión interpuso en 2018 un recurso de incumplimiento de especial relevancia ${ }^{82}$. Este cuestionaba la nueva Ley del Tribunal Supremo, que entre otras cosas, reducía la edad de jubilación de los jueces ${ }^{83}$. La particular determinación de la Comisión en este asunto se ponía de manifiesto por dos razones.

En primer lugar, porque a falta de una vulneración de otras disposiciones específicas de derecho de la Unión, la Comisión basaba el asunto en una interpretación ambiciosa del artículo 19.1. del TUE, que dispone que «los Estados miembros establecerán las vías de recurso necesarias para garantizar la tutela judicial efectiva en los ámbitos cubiertos por el Derecho de la Unión», en relación con el artículo 47 de la Carta, sobre la tutela judicial efectiva.

En segundo lugar, la Comisión actuaba con contundencia al solicitar al Tribunal de Justicia la adopción de medidas cautelares con el fin de restablecer la situación del Tribunal Supremo anterior a la fecha de la legislación en cuestión. La imposición de medidas cautelares en relación con una norma de un Estado miembro es de por sí algo muy inusual. Pero es que, además, en este caso la Comisión solicitaba que dichas medidas se adoptasen incluso antes de que Polonia hubiese presentado sus observaciones.

Un auto de la vicepresidenta del Tribunal de Justicia ${ }^{84}$, que sería más tarde confirmado por un auto definitivo, estimaba todas las peticiones de la Comisión y disponía que Polonia debía suspender inmediatamente la aplicación de las disposiciones relativas a la edad de jubilación. La decisión del Tribunal de Justicia, que cansado de la pasividad de las autoridades polacas venía desde hace tiempo "preparando progresivamente el terreno»" ${ }^{85}$, ha sido calificada de revolucionaria ${ }^{86}$. Mediante esta interpretación autónoma del artículo 19 el Tribunal sentaba las bases para realizar un control judicial del respeto del Estado de derecho y se instituía «en centinela de la independencia judicial de los Estados miembros» ${ }^{87}$. Esta vez, además, el auto tuvo un efecto inmediato en Polonia, cuyas autoridades permitieron que los jueces afectados se reincorporasen al Tribunal Supremo.

82 Sentencia de 24 de junio de 2019 en el asunto C-619/18, Comisión/Polonia, ECLI:EU:C:2019:531.

83 Idem.

84 Auto de la vicepresidenta de 19 de octubre de 2018 en el asunto C-619/18 R, ECLI:EU:C:2018:852. Auto definitivo de 17 de diciembre de 2018, ECLI:EU:C:2018:1021.

85 Blázquez (2019): 44, 49.

86 Sarmiento (2018).

87 García-Valdecasas (2019). 
Al auto siguió, en junio de 2019, la sentencia del Tribunal declarando el incumplimiento de Polonia, y en el mes de noviembre una segunda sentencia que, en virtud de la misma interpretación, declaraba contraria al ordenamiento jurídico de la Unión la Ley de Organización de los Tribunales Ordinarios ${ }^{88}$.

\section{CONCLUSIONES. SOBRE LA INSUFICIENCIA DE LOS NUEVOS PROCEDIMIENTOS Y LOS LÍMITES DE LA CAPACIDAD DE INFLUENCIA DE LA UNIÓN}

La quinta ampliación permitió a la Unión Europea ejercer una influencia sin precedentes en los países de Europa Central y Oriental. La condicionalidad de preadhesión fue muy eficaz para lograr la alineación de los países poscomunistas con la Unión Europea. Sin embargo, siendo la perspectiva de la adhesión el incentivo primordial de los candidatos, cabía temer que la influencia de la Unión decreciese tras la adhesión. Una vez que los candidatos se convirtieran en miembros de pleno derecho, las instituciones carecerían de instrumentos adecuados para ejercer su influencia en lo relativo a los principios de la democracia liberal y los derechos fundamentales.

El proceso de creación de nuevos mecanismos específicos para salvaguardar los valores de la Unión respondió en gran medida a la necesidad de cubrir el vacío que dejaba tras de sí el fin de la condicionalidad. Desde mediados de los años noventa, la Unión se fue dotando progresivamente de procedimientos con el fin de que sus instituciones pudiesen responder ante una eventual vulneración de los principios de la democracia liberal y los derechos fundamentales por parte de un Estado miembro.

Así se establecieron el procedimiento sancionador, el preventivo, y más recientemente, el Marco del Estado de Derecho. Los documentos preparatorios de la Conferencia Intergubernamental de Ámsterdam ponen de manifiesto en qué medida el nuevo procedimiento, que habría de permitir sancionar violaciones graves y persistentes de los valores europeos, respondía a la perspectiva de incorporar a doce Estados de menor madurez democrática. La inminencia de la quinta ampliación latía también tras el nuevo mecanismo preventivo introducido por la reforma de Niza para responder a un riesgo claro de violación de dichos valores, a pesar de la ironía de que la primera vez que se planteó seriamente tomar medidas de esta naturaleza el Estado afectado fuese Austria, una democracia consolidada.

88 Tribunal de Justicia, Sentencia de 5 de noviembre de 2019, Comisión contra Polonia, asunto C-192/18, ECLI:EU:C:2019:924. 
Cuando, unos meses antes de incorporarse a la Unión los Estados de Europa Central y Oriental, la Comisión procedía finalmente a detallar en una comunicación las condiciones de aplicación de los mecanismos preventivo y sancionador, dejaba fuera de duda la relación de causalidad existente entre la quinta ampliación y los nuevos procedimientos. Algunas voces en el Parlamento Europeo quisieron, con razón, recordar el principio de igualdad de los Estados miembros. También el establecimiento en 2014 del procedimiento de diálogo denominado Marco del Estado de Derecho respondió, en gran medida, a las primeras manifestaciones de la crisis húngara.

Del proceso que llevó al establecimiento de estos procedimientos cabe destacar las reticencias manifestadas ante lo que muchos consideraron una intromisión de la Unión en ámbitos reservados a la acción autónoma de los Estados. Ello contribuye a explicar los altos umbrales requeridos y el margen de apreciación política que les caracteriza. Conviene también señalar que los procedimientos sucesivamente establecidos pretendían completar y fortalecer el sistema de salvaguardia, y no debilitarlo sustituyendo el procedimiento sancionador por otros menos graves que no contemplan la imposición de sanciones.

Los nuevos procedimientos podrían haber tenido un carácter meramente disuasorio. Sin embargo, en los últimos ańos los valores europeos se han visto gravemente amenazados como consecuencia del auge de los populismos y la erosión de las democracias liberales, confirmando que no estaban de más. Los temores se han hecho realidad. Los Gobiernos de Hungría y Polonia han puesto en jaque los valores europeos, provocando la crisis del Estado de derecho más grave que ha atravesado nunca la Unión Europea.

Las medidas impulsadas por estos Gobiernos han afectado a la libertad de prensa, a los derechos de las minorías, a los solicitantes de asilo, a las organizaciones de la sociedad civil... y muy en particular, a la independencia del poder judicial. La particularidad de los movimientos nacional populistas en los países de Europa Central y Oriental, marcados por décadas de socialismo real y por sus recientes procesos de transición a la democracia, explican también el énfasis identitario y el marcado euroescepticismo que les caracteriza. Ello ha dificultado su relación con las instituciones europeas que, a su vez, son conscientes desde la crisis austriaca del efecto contraproducente que sus medidas pueden generar, despertando sentimientos nacionalistas.

En el caso de Hungría, la respuesta de las instituciones europeas se centró por mucho tiempo en el diálogo político y la apertura de procedimientos de infracción. La Comisión no activó el Marco del Estado de Derecho ni tampoco el mecanismo preventivo, manifestando una contención mayor que en el caso polaco. Solo en 2018 el Parlamento Europeo tomaba la decisión de 
activar el mecanismo preventivo, que quedaba pendiente de una decisión del Consejo que aún no tiene visos de adoptarse.

En el caso de Polonia la Comisión reaccionó con mayor premura iniciando en el Marco del Estado de Derecho y aprobando cuatro recomendaciones que fueron sucesivamente ignoradas por parte del Gobierno polaco. En 2017 iniciaba también el mecanismo preventivo que aún duerme a la espera de una decisión del Consejo. Frente a los limitados resultados de los procedimientos creados específicamente para salvaguardar los valores europeos, llama la atención el resultado de los recursos de incumplimiento interpuestos contra Polonia en 2018 y la contundencia y ambición con las que la Comisión y el Tribunal han actuado en ese marco.

Los casos húngaro y polaco nos dejan algunas enseñanzas amargas. Los umbrales requeridos por artículo 7 son excesivos, cosa que explica en gran medida la prudencia de las instituciones al recurrir a ellos, así como su limitado efecto disuasorio en los Estados afectados. A la espera de que su improbable modificación fortalezca el edificio construido para salvaguardar los valores europeos, queda el consuelo de comprobar que la Unión dispone de algunos instrumentos capaces de producir resultados cuando las instituciones actúan con determinación para defender los valores que son la base y el fundamento del proceso de integración. La Unión Europea es mucho más que un mercado interior o un proveedor de fondos. Es un espacio político basado en unos valores compartidos, la democracia, los derechos fundamentales y el Estado de derecho, cuya sistemática vulneración no es, en ningún caso, una cuestión meramente nacional.

Por último, años después de la quinta ampliación, cabe concluir que los recientes acontecimientos arrojan una sombra de duda sobre el poder transformador de la Unión. Ponen manifiesto, con especial intensidad, los límites de su capacidad de influencia después de la adhesión.

\section{Bibliografía}

Athisaari, M., Frowein J. y Oreja, M. (2000). Informe sobre Austria. Revista de Derecho Comunitario Europeo, 8, 775-814.

Balázs, P. (2009). Nuevos retos para la teoría de la integración: efectos de las ampliaciones de la Unión Europea sobre la integración. En J. M. Beneyto, J. Maíllo y B. Becerril. Tratado de Derecho y Políticas de la Unión Europea (t. I, pp. 303-342). Cizur Menor: Aranzadi.

Barroso J. M. (2011). Statement by President Barroso at the press conference following the meeting of the European Commission with the Hungarian Presidency. Speech /11/4.

— (2012). Discurso sobre el estado de la Unión. SPEECH/12/596. 
Blázquez Peinado, M.D. (2019). La UE ante las vulneraciones del Estado de derecho por parte del Estado polaco: panorámica general y estado actual de la cuestión. Revista General de Derecho Europeo, 48, 14-57.

Börzel, T. A. y Schimmelfennig, F. (2017). Coming together or drifting apart? The EU's political integration capacity in Eastern Europe. Journal of European Public Policy, 24 (2), 278-296. Disponible en: https://doi.org/10.1080/13501763.2016.1265574.

De Burca, G. (2004). Beyond the charter: How enlargement has enlarged the Human Rights policy of the European Union. Fordham International Law Journal, 27 (2), 679-714.

Closa, C. (2019). The politics of guarding the Treaties: Commission scrutiny of rule of law compliance. Journal of European Public Policy, 26 (5), 696-716. Disponible en: https:// doi.org/10.1080/13501763.2018.1477822.

Epstein, R. A. y Jacoby, W. (2014). Eastern enlargement ten years in: Transcending the EastWest divide? Journal of Common Market Studies, 52 (1), 1-16. Disponible en: https:// doi.org/10.1111/jcms.12089.

Epstein, R. A y Sedelmeier, U. (2008). Beyond conditionality: international institutions in postcommunist Europe after enlargement. Journal of European Public Policy, 15 (6), 795-805. Disponible en: https://doi.org/10.1080/13501760802196465.

García-Valdecasas, M. J. (2019). El Tribunal de Justicia, centinela de la independencia judicial desde la sentencia. Revista Española de Derecho Europeo, 72, 75-95.

Gateva, E. (2013). Post-accession conditionality translating benchmarks into political pressure? East European Politics, 29 (4), 420-442. Disponible en: https://doi.org/10.1080/2 1599165.2013 .836491$.

- (2018). European Union Enlargement Policy. Oxford Research Encyclopedia of Politics, 1-33. Disponible en: https://doi.org/10.1093/acrefore/9780190228637.013.504.

Inglehart R. y Norris, P. (2016). Trump, Brexit, and the Rise of Populism: Economic Have-Nots and Cultural Backlash. Harvard Kennedy School Working Paper, RWP16-026. Disponible en: https://doi.org/10.2139/ssrn.2818659.

Kochenov, D. (2019). Elephants in the Room: The European Commission's 2019 Communication on the Rule of Law. Hague Journal on the Rule of Law, 11, 423-438. Disponible en: https://doi.org/10.1007/s40803-019-00126-x.

Langrish, S. (1998). The Treaty of Amsterdam: selected highlights. European Law Review, 23, 3-19.

Mangas Martín, A. (1998). El Tratado de Ámsterdam: aspectos generales del pilar comunitario. Gaceta Jurídica de la Comunidad Europea y de la Competencia, D (29), 7-70. (2018). Polonia en el punto de mira: ‘solo riesgo grave de violación grave del Estado de derecho? Revista General del Derecho Europeo, 44, 1-12.

Martín de la Guardia, R. y Pérez Sánchez, G. (2019). Democracia sin liberalismo: el nacional-populismo en Hungría y Polonia (1990-2018). En A. Soto Carmona. La democracia herida. La tormenta perfecta. Madrid: Marcial Pons. Disponible en: https://doi. org/10.2307/j.ctv10sm8g8.8.

Martín y Pérez de Nanclares, J. (2019). La Unión Europea como comunidad de valores: a vueltas con la crisis de la democracia y del Estado de derecho. Teoría y Realidad Constitucional, 43, 121-159. Disponible en: https://doi.org/10.5944/trc.43.2019.24401. 
Merlingen, M., Mudde, C. y Sedelmeier, U. (2001). The Right and the Righteous? European Norms, Domestic Politics and the Sanctions Against Austria. Journal of Common Market Studies, 39, 59-77. Disponible en: https://doi.org/10.1111/1468-5965.00276.

Mudde, C. y C. Kaltwasser (2017). Populism. A Very Short Introduction. Oxford: Oxford University Press. Disponible en: https://doi.org/10.1093/actrade/ 9780190234874.001 .0001$.

Müller, J. W. (2017). El auge ¿¿imparable? Del populismo. La era de la perplejidad. Repensar el mundo que conocíamos. Madrid: BBVA.

Norris, P. y Inglehart, R. (2019). Cultural Backlash. In Cultural Backlash: Trump, Brexit, and Authoritarian Populism. Cambridge: Cambridge University Press. Disponible en: https://doi.org/10.1017/9781108595841.

Oreja Aguirre, M. (2019). Europa como comunidad de valores. Madrid: CEU Ediciones.

Papadimitriou, D., Baltag D. y Surubaru, N.C. (2017). Assessing the performance of the European Union in Central and Eastern Europe and in its neighbourhood. East European Politics, 33 (1), 1-16. Disponible en: https://doi.org/10.1080/21599165.2017.1279 608.

Pech, L. y Scheppele, K. L. (2017). Illiberalism within: Rule of Law backsliding within the EU. Cambridge Yearbook of European Legal Studies, 19, 3-47. Disponible en: https:// doi.org/10.1017/cel.2017.9.

Pérez Bernárdez, C. (2016). La Unión Europea frente a la erosión del Estado de derecho: las respuestas jurídico-políticas al caso polaco. Revista General de Derecho Europeo, 40, 48-95.

Pérez González, M. (1998). La Unión Europea y sus principios básicos. En M. Oreja Aguirre, F. Fonseca Morillo, El Tratado de Ámsterdam de la Unión Europea. Análisis y Comentarios (pp. 149-200). Madrid: Mc Graw Hill.

Reding, V. (2013a). The EU and the Rule of Law. What next? Centre for European Policy Studies, Bruselas. Speech/13/677.

- (2013b). Safeguarding the rule of law and solving the "Copenhagen dilemma": Towards a new EU-mechanism. Consejo de Asuntos Generales, Luxemburgo. Speech $/ 13 / 348$.

Sadurski, W. (2010). Adding bite to a bark? A story of Article 7, the EU enlargement, and Jörg Haider. The University of Sidney. Legal Studies Research Paper, 10 (1), 1-36.

Sarmiento, D. (2018). Interim revolutions. Verfassungsblog [blog], 22-10-2018. Disponible en: https://verfassungsblog.de/interim-revolutions/.

Sedelmeier, U. (2008). After conditionality: post-accession compliance with EU law in East Central Europe. Journal of European Public Policy, 15 (6), 806-825. Disponible en: https://doi.org/10.1080/13501760802196549.

Schimmelfennig, F. y Sedelmeier, U. (2004). Governance by conditionality: EU rule transfer to the candidate countries of Central and Eastern Europe. Journal of European Public Policy, 11(4), 661-679. Disponible en: https://doi.org/10.1080/13501760420002480 89.

Timmermans, F. (2017). Opening remarks: College readout on grave concerns about the clear risks for independence of the judiciary in Poland. Comunicado de prensa de la Comisión Europea, Bruselas, 19 de julio. 
Von Bogdandy, A. y Ioannidis, M. (2014). La deficiencia sistémica en el Estado de derecho: qué es, qué se ha hecho y qué se puede hacer. Revista de Estudios Políticos, 165, 19-64.

\section{Fuentes primarias}

Comisión de Venecia (2011). European Commission for Democracy Through Law. Opinion on the new Constitution of Hungary. Estrasburgo, 20 de junio de 2011. Dictamen 621/2011. CDL-AD (2011) 016.

Comisión de Venecia (2013). European Commission for Democracy Through Law. Opinion on the Fourth Amendement to the Fundamental Law. Estrasburgo, 17 de junio de 2013. Dictamen CDL-AD (2013) 012.

Comisión de Venecia (2016). European Commission for Democracy Through Law. Opinion on Amendments to the Act of $25^{\text {th }}$ of June 2015 on the Constitutional Tribunal of Poland. Venecia, 11 de marzo de 2016. Dictamen CDL-AD (2013)001.

Comisión de Venecia (2017). European Commission for Democracy Through Law. Opinion on the Draft Act Amending the Act on the National Council of the Judiciary, on the Draft Act Amending the Act on the Supreme Court, and on the Act on the organisation of Ordinary Courts. Estrasburgo, 11 de diciembre de 2017. Dictamen CDL-AD (2017) 031.

Comisión Europea (2003). Comunicación al Consejo y al Parlamento Europeo sobre el artículo 7 del TUE, de 15 de octubre de 2003. COM (2003) 0606 final.

Comisión Europea (2012). Statement of the European Commission on the situation in Hungary, de 11 de enero de 2012, MEMO/12/9.

Comisión Europea (2013). Comunicado de Prensa de 27 de marzo de 2013. COM (2013) 016.

Comisión Europea (2014). Comunicación al Parlamento Europeo y al Consejo. Un nuevo marco de la UE para reforzar el Estado de derecho, de 11 de marzo de 2014. COM (2014) 158 final.

Comisión Europea (2016a). Recomendación (UE) 2016/1374, de 27 de julio de 2016, relativa al Estado de derecho en Polonia. DO L 217 de 12-08-2016.

Comisión Europea (2016b). Recomendación (UE) 2017/146, de 21 de diciembre de 2016, sobre el Estado de derecho en Polonia que complementa la Recomendación (UE) 2016/1374. DO L 22 de 27-1-2017.

Comisión Europea (2017a). Recomendación (UE) 2017/1520, de 26 de julio de 2017, por lo que respecta al Estado de derecho en Polonia complementaria a las Recomendaciones (UE) 2016/1374 y 2017/146. DO L 228 de 2-9-2017.

Comisión Europea (2017b). Recomendación (UE) 2018/103, de 20 de diciembre de 2017, por lo que respecta al Estado de derecho en Polonia que complementa a las Recomendaciones (UE) 2016/1374, (UE) 2017/146 y 2017/1520. DO L 17 de 23-1-2018.

Comisión Europea (2017c). Propuesta de Decisión del Consejo relativa a la constatación de un riesgo claro de violación grave del Estado de derecho por parte de la República de Polonia, de 20 de diciembre de 2017. COM (2017) 835 final. 
Comisión Europea (2018). Propuesta de Reglamento del Parlamento Europeo y Consejo sobre la protección del presupuesto de la Unión en caso de deficiencias generalizadas del Estado de derecho en los Estados miembros, de 2 de mayo de 2018. COM (2018) 324 final.

Comisión Europea (2019). Comunicación de la Comisión al Parlamento Europeo, al Consejo Europeo y al Consejo. Reforzar en mayor medida el Estado de derecho en la Unión. Bruselas, de 3 de abril de 2019. COM (2019) 163 final.

Consejo de la Unión Europea (1995). Secretaría General, Informe del Grupo de Reflexión, Conferencia Intergubernamental de 1996, Bruselas, diciembre.

Ministerio de Asuntos Exteriores (1995). Conferencia intergubernamental de 1996: bases para una reflexión, Madrid.

Parlamento Europeo (2004a). Informe de la Comisión de Asuntos Constitucionales sobre la Comunicación de la Comisión sobre el artículo 7 del Tratado de la Unión Europea: respeto y promoción de los valores en los que está basada la Unión, de 1 de abril de 2004. A5-0227/2004.

Parlamento Europeo (2004b). Resolución sobre la Comunicación de la Comisión sobre el artículo 7 del Tratado de la Unión Europea: respeto y promoción de los valores en los que está basada la Unión, de 20 de abril de 2004, DO C 104E.

Parlamento Europeo (2016a). Resolución sobre la situación en Polonia, de 13 de abril de 2016. P8_TA (2016) 0123.

Parlamento Europeo (2016b). Resolución sobre los últimos acontecimientos en Polonia y su incidencia sobre los derechos fundamentales establecidos en la Carta de los Derechos Fundamentales de la UE, de 14 de septiembre de 2016. P8_TA (2016) 0344.

Parlamento Europeo (2017a). Resolución sobre la situación en Hungría, de 17 de mayo de 2017. P8_TA (2017)0216.

Parlamento Europeo (2017b). Resolución sobre la situación del Estado de derecho y la democracia en Polonia, de 15 de noviembre de 2017. P8_TA (2017) 0442.

Parlamento Europeo (2018). Resolución sobre una propuesta en la que solicita al Consejo que, de conformidad con el artículo 7, apartado 1, del Tratado de la Unión Europea, constate la existencia de un riesgo claro de violación grave por parte de Hungría de los valores en los que se fundamenta la Unión, de 12 de septiembre de 2018. P8_TA (2018) 0340 . 